International Journal of Management and Sustainability

2021 Vol. 10, No. 4, pp. 123-134.

$\operatorname{ISSN}(e):$ 2306-0662

$\operatorname{ISSN}(p):$ 2306-9856

DOI: 10.18488/journal.1 1.2021.104.123.134

(C) 2021 Conscientia Beam. All Rights Reserved.

check for
updates

\title{
CAN INSIDER STATUS PROMOTE EMPLOYEE VOICE BEHAVIOR?
}

(D) Shalendra S.
Kumar $^{1}$
(iD) Donghwa Jeon ${ }^{2}$
(iD) Shiu Lingam
(iD) Avenesh Pritam
Chand
(iD) Bonwoo $\mathbf{K u}^{5+}$

(n)

\section{Article History}

Received: 20 September 2021 Revised: 22 October 2021 Accepted: 25 November 2021 Published: 16 December 2021

\section{Keywords}

Perceived insider status Felt obligation behavio Employee voice behavior Social identity theory Pro-social behavior Constructive changes.

\author{
${ }^{\prime}$ Ph.D. Candidate, School of Business Administration, Chungnam National \\ University, Korea. \\ Email: salenkumar35@yahoo.com Tel: +8201085281978 \\ ${ }^{2}$ Department of International Trade, Chungnam National University, Korea. \\ Email:dhjeon@,cnu.ac.kr Tel:(+82)010-5018-7471 \\ ${ }^{3}$ Department of Accounting, Fiji National University, Fiji. \\ Email:shiu.lingam@fnu.ac.fj Tel:+6799480520 \\ ${ }^{4}$ Department of Economics and Customs, Fiji National University, Fiji. \\ Email: aveneshchand1979@gmail.com Tel: +6799516670 \\ ${ }^{5}$ School of Business Administration, Chungnam National University, Korea. \\ Email:kubonwoo@cnu.ac.krTel:(+82)010-4717-0023
}

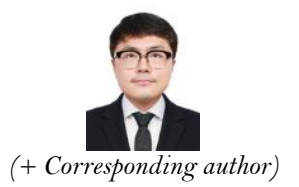

(+ Corresponding author $)$

\begin{abstract}
This research investigates employee voice behavior $(\mathrm{EVB})$ as a behavioral consequence of perceived insider status (PIS) through felt obligation behavior. Based on social identity theory, this research postulates that when employees realize that they are an insider, they tend to see themselves as a citizen of an organization and proactively engage in voice behavior. In order to evaluate this relationship, we collected 983 selfcompleted surveys from participants of public organizations in Fiji. The findings show that as insiders, employees unbegrudgingly engage in voice behavior when trying to provide corrective changes. This relationship was also partially mediated by felt obligation behavior (FOB). Interestingly, this study is the first one to use social identity theory to explain how employees form close attachment to the organizations they work for, driving greater feelings of belongingness and altering their behavior to engage in voice behavior. Therefore, we find social identity theory to be very relevant in explaining the relationship between PIS and EVB through FOB. This makes a significant contribution to the social identity theory. Finally, the current study offers practical implications, limitations, and further research directions.
\end{abstract}

Contribution/Originality: This study contributes to extant literature by investigating how an employee, who perceives himself or herself as an insider, has a greater potential of promoting voice behavior in an organization. In addition, the current study also shows that the relationship between perceived insider status and voice behavior is partially strengthened by felt obligation.

\section{INTRODUCTION}

"To be inside a place is to belong to it and identify with it, and the more profoundly inside you are, the stronger the identity is with the place" Relph (1976).

To be an insider means belong to a place and highly identify with it. The more you identify, the more personal space is earned within the organization. In other words, when an individual realizes that they are an insider, they tend to see themselves as a citizen of an organization and participate more in extra-role behavior. As such, perceived insider status (PIS) is defined as the degree to which an employee considers himself or herself as a member, and has a sense of belonging and identification within the workplace setting (Chen \& Aryee, 2007; Sui \& Wang, 2014). PIS enables an individual to share experiences without restriction and establish a greater sense of psychological 
belongingness. Therefore, PIS is regarded as an important driver of employee behavior.

According to prior studies, PIS is linked to various individual outcomes, such as organizational citizenship behavior, low deviance behavior (Stamper \& Masterson, 2002), organizational commitment (Lapalme, Stamper, Simard, \& Tremblay, 2009), intention to stay (Armstrong-Stassen \& Schlosser, 2011), social integration, and task performance (Wang \& Kim, 2013). In addition, a study by Hongli, Feng, Prevellie, \& Wu (2017) used role identity theory to highlight that PIS through FOB can drive innovative behavior. While we acknowledge their finding, we employ social identity theory to explain that PIS through FOB can also stimulate other proactive behavior because PIS is known for fostering a sense of belongingness and positively contributing toward various employee outcome behavior. The extant literature has overlooked the possibility that PIS can also drive employee voice behavior (EVB). We argue that employee voice behavior is a proactive behavior in the form of challenge-oriented organizational citizenship behavior (OCB) (Burris, 2012; Detert, Burris, Harrison, \& Martin, 2013; Liu, Song, Li, \& Liao, 2017; Ng \& Feldman, 2012) for the following reasons: First, voice behavior is a proactive, future-oriented and extra-role behavior that makes things happen in an organization (Frese \& Fay, 2001). Second, it improves unit functions through constructive changes (Burris, Detert, \& Chiaburu, 2008; Detert \& Burris, 2007; Detert \& Treviño, 2010; LePine \& Van Dyne, 1998). Finally, it instills group learning (Argyris \& Schon, 1978; Edmondson, 1999). Hence, we pose an important question: How can perceived insider status drive an individual to engage in voice behavior? We draw attention to social identity theory to address this pertinent question.

Based on social identity theory (Tajfel \& Turner, 1979; Tajfel \& Turner, 1986), when an employee highly identifies as a member of social aggregate, they develop a purpose of understanding and have a sense of belonging in the social environment. They are ready to alter their behavior and work in a collective (Turner \& Onorato, 1999). This suggests that when an individual strongly identifies with the team, they show a high level of task performance, more creativity, and they engage more in extra-role behavior, such as OCB (Dalal, 2005; Organ, 1988). Social identity theory (Tajfel, 1982) also postulates that when employees identify with the organization, they develop selfesteem and pride from the image associated with the organization, which enables them to fulfill their self-worth. As such, an individual's identification with organizational values creates an emotional bond and enhances social interaction that can facilitate proactive behavior (Alvesson \& Kärreman, 2001) such as employee voice behavior. Furthermore, the relationship between PIS and EVB is strengthened by the mediating the role of felt obligation behavior (FOB). FOB acts as a "bridge" linking PIS and EVB. Prior literature has demonstrated that felt obligation is a powerful driver affecting coworkers' behavior (Zhou \& George, 2001). As such, felt obligation provides an impetus that coworkers will behave in such a way that is congruent with one's own beliefs and demonstrate behavior that contributes to organizational effectiveness.

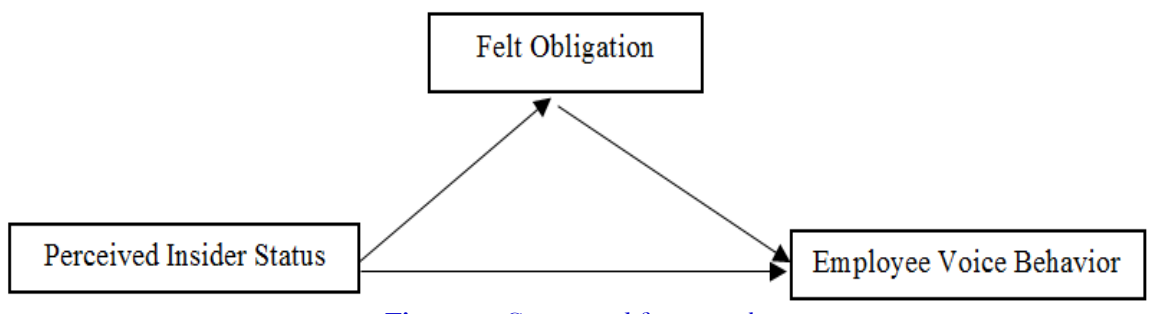

Figure-1. Conceptual framework.

The current study suggests that coworkers with high PIS and FOB will establish a greater sense of intimacy with the organization and show more engagement in voice behavior. The conceptual framework shown in Figure 1 provides the basic foundation for the current study. The cross-sectional data consisting of 983 samples were collected from public organizations in the island economy of Fiji. The study concludes by presenting theoretical and practical implications, showing that perceived insider status and employee voice behavior are strengthened by the mediating role of felt obligation. Finally, some suggestions for managerial improvement are also provided. 


\section{THEORETICAL BACKGROUND}

\subsection{Perceived Insider Status and Knowledge Sharing Behavior}

Perceived insider status (PIS) fosters a greater sense of belongingness that encourages coworkers to highly identify with their team and the organization. They identify their personal space and begin to explore ways to effectively contribute to organizational success (Stamper \& Masterson, 2002). Prior studies have highlighted that PIS is linked to organizational citizenship behavior, low deviance behavior (Stamper \& Masterson, 2002), organizational commitment (Lapalme et al., 2009), intention to stay (Armstrong-Stassen \& Schlosser, 2011), social integration, task performance (Wang \& Kim, 2013), and innovative behavior (Hongli et al., 2017). PIS is also an important driver for employee outcome behavior. Extant literature has overlooked the possibility that employee voice behavior can also be a behavioral consequence of PIS. As such, we argue that employee voice behavior is a proactive behavior in the form of challenge-oriented organizational citizenship behavior (OCB) that can suggest constructive changes for the organization (Burris, 2012; Burris et al., 2008; Detert et al., 2013; Detert \& Burris, 2007; Detert \& Treviño, 2010; LePine \& Van Dyne, 1998; Liu et al., 2017; Ng \& Feldman, 2012) and encourage group learning (Argyris \& Schon, 1978; Edmondson, 1999).

Furthermore, scholars have highlighted that perceived insider status can promote the notion of proactive behavior (Stamper \& Masterson, 2002). Hence, proactive behaviors are described as "taking initiative in improving the current circumstances or creating new ones" (Crant, 2000). Being proactive in nature, employee voice behavior is described as expressing one's thoughts, ideas, opinions, and suggestions for constructive changes in the organization (Dyne, Ang, \& Botero, 2003; Hongli et al., 2017). Having identified personal space in the organization, employees develop a greater sense of obligation and intimacy, and naturally, this motivates employees to proactively engage in voice behavior (Hongli et al., 2017). Similarly, Van Dyne \& LePine (1998) elucidated that when coworkers receive fair treatment from the organization, such as respect, which is not peripheral, they feel attached to the organization and adopt more voice behaviors. Therefore, we pose an important question: How can perceived insider status drive an individual to engage in employee voice behavior? We draw attention to social identity theory to address this pertinent question.

Based on principles of social identity theory (Tajfel, 1982), when employees highly identify with a group or organization, they develop a desire to be part of it and derive self-esteem and pride from the image associated with a group or organization, which enables them to fulfill their self-worth. Hence, an individual's identification with a group or organizational values creates an emotional bond, enhances social interaction, and facilitates proactive behavior (Alvesson \& Kärreman, 2001). Based on the findings of various scholars, we argue that when individuals feel secure in their jobs, they invest more time, and show commitment and enthusiasm in expressing ideas and offering suggestions without hesitation. Thus, proactively engaging in voice behavior provides an ultimate platform for personal satisfaction, enhances self-image, and enables an individual to feel an attachment to the organization. Dubois, Rucker, \& Galinsky (2015) argued that when employees feel that the organization values and respects their suggestions and contributions, this is seen as a signal that serves as "motive to obtain respect or admiration from others" making them feel like more valuable members (Dubois et al., 2015). Employees with a high level of perceived insider status feel more important and central to the organization. They are more willing to modify their behavior and engage more in creative and proactive behavior (Hui, Lee, \& Wang, 2015; Liao, 2015; Sui \& Wang, 2013), while employees with low perceived insider status have weak ownership and feel alienated from other employees and the organization (Chen \& Aryee, 2007). Therefore, we predict that perceived insider status is an antecedent of employee voice behavior.

H1: Perceived insider status (PIS) is positively related to employee voice behavior (EVB).

PIS is a perception of forming an intimacy with an organization. As such, when an organization treats its employees with trust, they form an intimacy with the organization, perceive a sense of acceptance, and increase the likelihood of contribution (Hongli et al., 2017; McMillan \& Chavis, 1986). This suggests that employees with high 
felt obligation behavior (FOB) believe that they have an obligation to behave incongruently with values in upholding organizational expectations. In addition, when an employee perceives obligation, they increase their responsibility without a pay rise or unexpected sufferings from unrealistic sufferings. As suggested by Zhou \& George (2001), PIS provides an impetus for employee behavior and they will behave incongruently with their beliefs. Furthermore, high PIS has the potential to increase job performance, social integration, and motivation to display more proactive behavior (Chen \& Aryee, 2007; Hongli et al., 2017; Ng \& Feldman, 2015). Consequently, when employees experience harmony with the organizational system and realize a greater sense of belonging, they feel more attachment, and such employees feel obligated to engage more in proactive behavior. On this basis, we propose the following hypothesis:

H2: Perceived insider status (PIS) is positively related to felt obligation (FOB).

\subsection{The Mediating Role of Felt Obligation Behavior}

When employees perceive that they have a strong attachment to the organization, the conscientiousness of roles and responsibilities tends to promote a positive self-image and they engage more in proactive behavior in enhancing the organizational goals and values (Hongli et al., 2017; Ng \& Feldman, 2015). Similarly, greater respect from the organization may also lead to more commitment and voluntary behaviors (Van Dyne \& LePine, 1998). Therefore, it's obvious that FOB is pro-social behavior that can promote other proactive behaviors $(\mathrm{Ng} \&$ Feldman, 2015). Additionally, we argue that PIS will increase employees' FOB and, as such, will be more engaged in employee voice behavior (EVB). Furthermore, when individuals are aware of their FOB, they will be more actively involved in serving the interests of the organization and be more likely to engage in proactive behavior associated with the organization's values (Zhou \& George, 2001). Similarly, Armeli, Eisenberger, Fasolo, \& Lynch (1998) found that the feeling of indebtedness to an organization reduces staff turnover and withdrawal behavior, and encourages the adoption of more proactive behaviors. When an employee perceives a strong propensity to facilitate their social world, it creates a positive self-image, generates an innate feeling of roles and responsibilities and prosocial behavior, and creates stronger ties (Den Hartog \& Belschak, 2007; Hongli et al., 2017). Hence, FOB has been perceived as a form of internal motivation that drives an individual to exhibit positive behaviors (Fuller, Marler, \& Hester, 2006). Therefore, we suggest that FOB moderates the relationship between PIS and EVB.

Based on the perspective of social identity theory (SIT), when employees highly identify as a member of social aggregate they tend to develop a greater understanding and a greater sense of belonging, and they are willing to alter their behavior and work collectively towards mutual goals in a social environment (Tajfel \& Turner, 1979; Tajfel \& Turner, 1986; Turner \& Onorato, 1999). In this vein, when an individual strongly identifies with the team, they show a high level of performance, more creativity, and extra-role behavior. Therefore, based on the principle of SIT, similar to OCB, individuals who highly identify with the organization and team will engage more in voice behavior. Furthermore, the relationship between PIS and EVB is strengthened by mediating the role of felt obligation behavior (FOB). We expect FOB to act as a "bridge" linking PIS and EVB. Prior literature has demonstrated that felt obligation is a powerful driver affecting coworkers' behavior (Zhou \& George, 2001). As such, felt obligation provides an impetus that coworkers will behave in such a way that is congruent with their own beliefs and demonstrate behavior contributing to organizational effectiveness. Thus, we contend that having been realized as "responsible citizens", employees become obliged to serve the organization's interests and protect the organization from harm. Alternatively, they will engage more in proactive behaviors, such as EVB. In this vein, FOB is expected to mediate the relationship between PIS and EVB.

H3: Felt obligation (FOB) is positively related to employee voice behavior (EVB).

In addition, we propose that there is a mediation effect in the proposed model, as such we posit the following hypothesis:

H4: Felt obligation (FOB) mediates the relationship between perceived insider status (PIS) and employee voice behavior (EVB) 
and, as such, FOB will strengthen the relationship between PIS and EVB.

\section{METHOD}

\subsection{Sample}

An online survey was used to collect data from 983 public employees from the island economy of Fiji. The respondents filled in the survey and returned the completed form in a sealed envelope. No missing data was reported. Our control variables were salary scale, age, gender, and occupational experience. In addition, we coded gender as the dummy variable $(0=$ male, $1=$ female $)$. Male participants comprise $52.7 \%$ of respondents, while 47.3 $\%$ are female. The age categories are divided as follows: 18-26 years (12.6\%), 27-30 years (35.8\%), 31-34 years (20.5\%), 35-38 years (12.5\%), and 39 years and above (18.6\%). The organizational experience categories are: $1-7$ years (14.2\%), 8-13 years (31.8\%), 14-19 years (28.2\%), 20-25 years (9.6\%), 26-31 years (12.5\%), and 32 years and over $(3.7 \%)$. The salary scale is split as follows: less than \$10,000 Fj (8.1\%), \$11,000 Fj-\$26,000 Fj (22.3 \%), $\$ 27,000 \mathrm{Fj}-\$ 31,000 \mathrm{Fj}(46.5 \%), \$ 32,000 \mathrm{Fj}-\$ 36,000 \mathrm{Fj}(19.5 \%)$, and above $\$ 37,000 \mathrm{Fj}(3.6 \%)$.

\subsection{Measurements}

A five-point Likert scale ranging from 1 (strongly disagree) to 5 (strongly agree) was used to collect data. The participants responded on perceived insider status, employee voice behavior, and felt obligation behavior.

3.3. Perceived Insider Status (PIS)

A four-item Likert scale, by Stamper \& Masterson (2002), was used to measure PIS with the following sample phrase: "My work organization makes me believe that I am included in it." Cronbach's $\alpha$ was 0.87.

\subsection{Employee Voice Behavior (EVB)}

A seven-item Likert scale, by Van Dyne and LePine (1998), was used to measure EVB with the following sample phrase: "This employee develops and makes recommendations concerning issues that affect this working group." Cronbach's $\alpha$ was 0.91 .

\subsection{Felt Obligation Behavior (FOB)}

A six-point Likert scale by Eisenberger, Armeli, Rexwinkel, Lynch, \& Rhoades (2001) measured FOB with sample phrases, such as "I feel a personal obligation to do whatever I can to help my company achieve its goals." Cronbach's $\alpha$ was 0.87 .

\subsection{Control Variables}

We controlled several variables, such as age, occupational experience, and gender, which had some effect in determining the employee behavioral outcome (Flynn, Reagans, Amanatullah, \& Ames, 2006; Spector \& Brannick, 2011; Srivastava, Bartol, \& Locke, 2006). The results are illustrated in Table 1. We coded gender as a dummy variable $(0=$ male, 1 = female $)$, age and occupation. Experience in years, and salary in Fijian dollars (FJ). The descriptive statistic shows that perceived insider status (PIS) was positively related to employee voice behavior (EVB). Furthermore, we mediated the relationship through felt obligation behavior (FOB) and as predicted, FOB partially mediated the relationship between PIS and EVB. Finally, the analysis showed that occupation and salary were positively associated with PIS and EVB. 
Table-1. Descriptive statistics.

\begin{tabular}{|c|c|c|c|c|c|c|c|c|}
\hline & Mean & SD & 1 & 2 & 3 & 4 & 5 & 6 \\
\hline 1. Age & 2.20 & 0.85 & & & & & & \\
\hline 2. Gender & 1.64 & 0.70 & $-0.089^{* *}$ & & & & & \\
\hline 3. Occupation & 2.02 & 0.77 & $0.733^{* * *}$ & $-0.155^{* *}$ & & & & \\
\hline 4. Salary & 2.71 & 0.79 & $0.300^{*}$ & 0.033 & 0.347 ** & & & \\
\hline 5. Perceived Insider Status & 3.71 & 0.94 & -0.004 & -0.022 & 0.036 & 0.035 & & \\
\hline 6. Employee Voice & 3.94 & 0.92 & $0.156^{* * *}$ & -0.042 & $0.186^{*}$ & $0.155^{*}$ & $0.445^{* *}$ & \\
\hline 7. Felt Obligation & 3.28 & 0.95 & $-0.081^{*}$ & 0.032 & -0.039 & -0.024 & $0.628 * *$ & $0.278 * *$ \\
\hline
\end{tabular}

\section{DATA ANALYSIS AND RESULTS}

As Anderson \& Gerbing, (1988) recommended, we analyzed the average variance extracted (AVE), construct validity, and composite reliability $(\mathrm{CR})$, before testing the proposed hypotheses. All items in the survey showed significant factor loading (see Table 4). In addition, Table 4 also shows that the AVE ranges from 0.53 to 0.68 , which exceeded the recommended threshold level of 0.5. Furthermore, composite reliability (CR) met the threshold of 0.70 (Fornell, 1981) and Cronbach's alpha exceeded 0.7. Confirmatory factor analysis (CFA) was used to check the distinctiveness of the measured variables, while the analysis of moment structures (AMOS) was used to determine the comparative fit index (CFI), chi-square (Anderson \& Gerbing, 1988), Tucker-Lewis index (TLI), and the root mean square error of approximation (RMSEA). The summary of the model fit is shown in Table 2.

Table-2. The model fit.

\begin{tabular}{c|c|cc|c|c|c}
\hline$x^{2}$ & df & RAMSEA & RMR & TLI & IFI & CFI \\
\hline 347.237 & 87 & 0.055 & 0.026 & 0.963 & 0.970 & 0.970 \\
\hline
\end{tabular}

Common method bias (CMB) can be a critical issue in survey data, and this normally occurs when crosssectional data is collected. Nevertheless, this can be mitigated via a procedural method and statistical tools (Podsakoff, MacKenzie, \& Podsakoff, 2012). First, through the procedural method, our study separated predictor variables from other constructs, and we maintained respondents' anonymity. Second, in order to exclude CMB, a series of confirmatory factor analyses was performed. Prior studies have highlighted that a correlation of more than 0.9 indicates the presence of CMB (Bagozzi \& Yi, 1990).

Table-3. Matrix of loading and cross-loading

\begin{tabular}{|c|c|c|c|}
\hline Item & PIS & EVB & FOB \\
\hline PIS 1 & $0.704 * *$ & $0.475^{* *}$ & 0.399** \\
\hline PIS 2 & $0.726^{* * *}$ & $0.401^{* * *}$ & $0.551^{* * *}$ \\
\hline PIS 3 & $0.721 * *$ & $0.402^{*} *$ & $0.603^{* * *}$ \\
\hline PIS 4 & $0.731^{* *}$ & $0.412^{* *}$ & $0.448 * *$ \\
\hline EVB 1 & $0.751^{*} *$ & $0.773^{*} *$ & $0.356^{* * *}$ \\
\hline $\mathrm{EVB} 2$ & $0.641 * *$ & $0.780^{* * *}$ & $0.434^{* * *}$ \\
\hline EVB 3 & $0.633^{*} *$ & $0.785^{* * *}$ & O393** \\
\hline $\mathrm{EVB} 4$ & $0.682 * *$ & $0.783^{*} *$ & 0.411 *** \\
\hline EVB 5 & $0.721^{* *}$ & $0.714^{* * *}$ & $0.414^{* * *}$ \\
\hline EVB 6 & $0.734^{* *} *$ & $0.723^{*} *$ & $0.382^{* *}$ \\
\hline EVB 7 & $0.658 * *$ & $0.704 * *$ & $0.429 * *$ \\
\hline FOB 1 & $0.411^{* *}$ & $0.421 * *$ & $0.792^{* *}$ \\
\hline FOB 2 & $0.413^{* *}$ & $0.392^{* *}$ & $0.788^{* * *}$ \\
\hline FOB 3 & $0.405^{* *}$ & $0.400^{* * *}$ & $0.731^{* * *}$ \\
\hline $\mathrm{FOB} 4$ & $0.475^{* * *}$ & $0.451^{* * *}$ & $0.793 * *$ \\
\hline FOB 5 & $0.411^{* * *}$ & $0.359^{* *}$ & $0.735^{* * *}$ \\
\hline FOB 6 & $0.401^{* *}$ & $0.403^{* * *}$ & $0.743^{*} *$ \\
\hline
\end{tabular}

$\mathrm{PIS}=$ perceived insider status, $\mathrm{EVB}=$ employee voice behavior, $\mathrm{FOB}=$ felt obligation behavior. 
Table 3 shows that the correlations within the construct were only as high as 0.793 , which does not exceed 0.90. The common latent factor (CFL) was used to check standardized regression weights, and the variance was minuscule (see Table 4). Finally, the overall data showed no threat of CMB. The proposed research framework was tested through conditional process analysis (CPA) (Hayes, 2018).

Table-4. Factor loading with confirmatory factor analysis (CFA).

\begin{tabular}{|c|c|c|c|c|c|c|c|c|}
\hline Item & Mean & SD & $\begin{array}{l}\text { Item total } \\
\text { correlation }\end{array}$ & Loading & Error & $\begin{array}{c}\text { Cronbach's } \\
\text { alpha }\end{array}$ & $\begin{array}{l}\text { Composite } \\
\text { reliability }\end{array}$ & AVE \\
\hline PIS 1 & 3.83 & 0.742 & 0.401 & 0.839 & 0.031 & \multirow{4}{*}{0.87} & \multirow{4}{*}{0.87} & \multirow{4}{*}{0.64} \\
\hline PIS 2 & 3.87 & 0.746 & 0.421 & 0.848 & 0.032 & & & \\
\hline PIS 3 & 3.74 & 0.774 & 0.352 & 0.856 & 0.033 & & & \\
\hline PIS 4 & 3.80 & 0.711 & 0.366 & 0.648 & 0.034 & & & \\
\hline EVB 1 & 3.82 & 0.745 & 0.439 & 0.865 & 0.031 & \multirow{7}{*}{0.90} & \multirow{7}{*}{0.89} & \multirow{7}{*}{0.68} \\
\hline $\mathrm{EVB} 2$ & 3.96 & 0.796 & 0.532 & 0.854 & 0.029 & & & \\
\hline EVB 3 & 3.77 & 0.757 & 0.458 & 0.876 & 0.035 & & & \\
\hline EVB 4 & 3.84 & 0.794 & 0.491 & 0.683 & 0.031 & & & \\
\hline EVB 5 & 3.42 & 0.729 & 0.401 & 0.745 & 0.031 & & & \\
\hline EVB 6 & 3.51 & 0.879 & 0.425 & 0.755 & 0.029 & & & \\
\hline EVB 7 & 3.81 & 0.913 & 0.415 & 0.732 & 0.030 & & & \\
\hline FOB 1 & 3.26 & 0.894 & 0.478 & 0.816 & 0.044 & \multirow{6}{*}{0.87} & \multirow{6}{*}{0.81} & \multirow{6}{*}{0.53} \\
\hline FOB 2 & 3.19 & 0.777 & 0.456 & 0.761 & 0.043 & & & \\
\hline FOB 3 & 3.21 & 0.856 & 0.478 & 0.645 & 0.038 & & & \\
\hline $\mathrm{FOB} 4$ & 3.41 & 0.843 & 0.469 & 0.661 & 0.042 & & & \\
\hline FOB 5 & 3.82 & 0.742 & 0.491 & 0.839 & 0.041 & & & \\
\hline FOB 6 & 3.90 & 0.746 & 0.441 & 0.848 & 0.029 & & & \\
\hline
\end{tabular}

H1 hypothesizes that perceived insider status (PIS) has a positive correlation with employee voice behavior (EVB). The results of the analysis (see Table 5) show that PIS is positively associated with EVB $(\beta=0.287, \mathrm{p}<$ 0.001); therefore, $\mathrm{H} 1$ is fully supported. Second, perceived insider status (PIS) is hypothesized to positively correlate with felt obligation $(\mathrm{FOB})$, and the results confirm that this is the case $(\beta=0.314, \mathrm{p}<0.001)$; therefore, $\mathrm{H} 2$ is fully supported. Third, we hypothesized that felt obligation (FOB) is positively related to employee voice behavior (EVB). The results show that FOB is positively associated with $\mathrm{EVB}(\beta=0.554, \mathrm{p}<0.001)$; therefore, H3 is fully supported. Finally, we hypothesized that felt obligation (FOB) mediates the relationship between perceived insider status (PIS) and employee voice behavior (EVB), and, as such, we expect FOB to strengthen the relationship between PIS and EVB. The results show that FOB partially mediates the relationship between PIS and EVB ( $\beta=$ $0.462, \mathrm{p}<0.001)$; therefore, $\mathrm{H} 4$ is partially supported.

Table 5. Mediation of felt obligation between perceived insider status (PIS) and employee voice behavior (EVB).

\begin{tabular}{|c|c|c|c|c|c|c|c|c|c|}
\hline Parameter & Dependent & $\mathbf{R}^{2}$ & $\mathbf{F}$ & $\mathbf{P}$ & Coefficient & SE & $\mathrm{t}$ & LLCI & ULCI \\
\hline Constant & \multirow{2}{*}{$\mathrm{FOB}$} & \multirow{2}{*}{0.0956} & \multirow{2}{*}{20.63} & \multirow{2}{*}{0.000} & $2.7700 * * *$ & 0.1556 & 17.7978 & 2.4645 & 3.0754 \\
\hline PIS & & & & & $0.3140 * * *$ & 0.0323 & 9.7088 & 0.2505 & 0.3774 \\
\hline Constant & \multirow{3}{*}{$\mathrm{EVB}$} & \multirow{3}{*}{0.4591} & \multirow{3}{*}{137.08} & \multirow{3}{*}{0.000} & $0.5890^{* * * *}$ & 0.1404 & 4.1944 & 0.3134 & 0.8645 \\
\hline PIS & & & & & $0.2873^{* * *}$ & 0.0265 & 10.8230 & 0.2352 & 0.3394 \\
\hline FOB & & & & & $0.5547 * * *$ & 0.0251 & 22.1062 & 0.5055 & 0.6040 \\
\hline \multicolumn{10}{|c|}{ Direct effect of $\mathrm{X}$ to $\mathrm{Y}$} \\
\hline & & & & & $0.2873^{* * *}$ & 0.0265 & 10.8230 & 0.2352 & 0.3394 \\
\hline \multicolumn{10}{|c|}{ The indirect effect of $\mathrm{X}$ to $\mathrm{Y}$} \\
\hline & & & & & 0.1742 & 0.0269 & & 0.1227 & 0.2281 \\
\hline \multicolumn{10}{|c|}{ Total effect of $\mathrm{X}$ to $\mathrm{Y}$} \\
\hline & & & & & $0.4615^{* * *}$ & 0.0310 & 14.8648 & 0.4006 & 0.5224 \\
\hline
\end{tabular}

Note: $* \mathrm{p}<0.05 * * \mathrm{p}<0.01, * * * \mathrm{p}<0.001$. Bootstrapped Sample $=5,000, \mathrm{CI}=95 \%$.

Dependent Variable: $\mathrm{EVB}=$ Employee voice behavior.

** $\mathrm{p}<0.01,{ }^{* * *} \mathrm{p}<0.001$. Dummy variables: Gender $(0=$ male, $1=$ female $)$, age, occupational experience, salary scale; PIS $=$ perceived insider status, FOB $=$

felt obligation behavior. 


\section{DISCUSSION AND CONCLUSION}

The current study examined the mediated relationship between PIS and EVB through felt obligation behavior. The analysis shows that FOB partially mediates the relationship, which, in turn, enhances employee voice behavior. This suggests that FOB is a pro-social behavior that has the potential to promote proactive behavior.

\subsection{Theoretical Contributions}

The current study shows that perceived insider status has a greater potential to promote employee voice behavior, while it was obvious that incentives were major factors driving proactive behavior. However, this study shows that when employees identify with the organization, they also identify personal space in the organization and begin to explore ways to contribute towards achieving organizational goals. However, voice behavior is seen as a risky behavior that could upset organizational settings (Kassing, 1997; Kassing, 1998; Kassing, 2011; Morrison \& Milliken, 2003). Yet, social identity theory (Tajfel, 1982) postulates that when employees highly identify with an organization, they develop a desire to be part of it. This drives and derives self-esteem and pride from the image associated with the organization enabling employees to fulfill their self-worth. Therefore, when individuals are perceived to be secure with an organization, they invest more time, show more commitment, and are more willing to express ideas and suggestions. Social identity theory further explains that when employees have more attachment towards the organization, it produces a greater feeling of belongingness, leading to more proactive behavior (e.g., employee voice behavior) (Hui et al., 2015; Liao, 2015; Tajfel, 1982). Therefore, we find social identity theory to be very relevant in explaining the relationship between PIS and EVB. This is our most significant contribution towards social identity theory.

Finally, our study also shows that felt obligation behavior partially mediated the relationship between PIS and EVB. The mediation effect shows that FOB is a pro-social behavior that has the potential to promote proactive behaviors (Hongli et al., 2017; Ng \& Feldman, 2015). As such, when employees are aware of their obligations, they will become actively involved in serving the interests of the organization and at the same time proactively engage with organizational values and beliefs (Zhou \& George, 2001). As such, internal motivation drives an individual to exhibit more desirable behavior, such as employee voice behavior

Based on the perspective of social identity theory (Tajfel \& Turner, 1979; Tajfel \& Turner, 1986), when employees identify as members of a social aggregate, they develop a greater understanding and a sense of belonging, and they are willing to alter their behavior and work collectively (Tajfel \& Turner, 1979; Tajfel \& Turner, 1986; Turner \& Onorato, 1999). Prior literature has highlighted that felt obligation is a powerful driver that affects employee behavior (Zhou \& George, 2001). The current study shows that presence of FOB is a mediator, and the total effect of PIS on EVB was enhanced. As such, felt obligation provides an impetus that coworkers will behave in such a way that is congruent with their own belief and demonstrate behavior forming an obligation to effectively contribute towards organizational success. Finally, social identity theory highlights that when employees identify with the organization, it creates an emotional bond, enhances social interaction, and facilitates proactive behavior (Alvesson \& Kärreman, 2001; Tajfel, 1982), such as employee voice behavior. As such, explaining the mediation effect of FOB between PIS and EVB is also a major contribution towards social identity theory. In summary, social identity can be used to explain how insider status is vital for employee voice behavior.

\subsection{Practical Implications}

The current study shows the importance of PIS in promoting employee voice behavior, while providing incentives may bring some practical solutions. However, this can only be assumed when individuals engage in voice behavior caused by certain external stimuli, such as a sacrifice for their own interest, or a gain from incentives. In addition to the above, we suggest that organizations need to provide more emotional incentives, a feeling that everything is right in an employee's life by treating employees as family members and supporting them during 
difficult times. Organizations could also allow activities outside normal working hours in order to release tension and stress in an informal setting. Additionally, management could encourage more job rotations and reduce or share workloads. Prior studies have highlighted that high workloads have a significant effect on employee performance (Rajan, 2018). The current study indicates that perceived insider status is more of a communitarian culture, which can encourage more proactive behavior.

\subsection{Limitations and Future Research Direction}

Although our findings make a key contribution to the extant literature, certain limitations need to be addressed. First, based on cross-sectional data, our analysis did not allow casual interference. However, future studies should collaborate the causality among given variables with controlled experiments or longitudinal data. Second, employee voice behavior needs to be praised. According to Mikulincer, Shaver, Sapir-Lavid, \& AvihouKanza (2009), praise from leaders was found to be the best motivator, beating financial and other non-cash incentives (Mikulincer et al., 2009). Praising individuals not only encourages them but make them more effective. Consultancy.uk (2015) suggested that organizations that actively recognize and reward employees have business outcomes that are twelve times stronger. Future research could investigate recognition and praise in organizations as this may show how voicing behavior can be developed further. Finally, the generalization of our study should be executed with caution as the current sample is from Fiji Island. The findings suggest that because of cultural context, compared to males, females showed a lower level of resource-sharing behavior. Ostentatious voice behavior is regarded as socially unsuitable as modesty is respected as a virtue and such norms tend to place females into passive roles (Hofstede, 1991). A survey in Western reported that voice behavior between males and females was not significantly different (Cabrera, Collins, \& Salgado, 2006). Future studies could include gender and national culture in examining the generalizability across different cultural settings, and perceived insider status could be further explored by establishing a rich array of alternative pathways leading to other behavioral outcomes in an organizational setting.

Funding: This work was supported by the BK21 FOUR Program and Chungnam National

University Research Grant, 2021

Competing Interests: The authors declare that they have no competing interests.

Acknowledgement: All authors contributed equally to the conception and design of the study.

\section{REFERENCES}

Alvesson, M., \& Kärreman, D. (2001). Odd couple: Making sense of the curious concept of knowledge management. Journal of Management Studies, 38(7), 995-1018. Available at: https://doi.org/10.1111/1467-6486.00269.

Anderson, J. C., \& Gerbing, D. W. (1988). Structural equation modeling in practice: A review and recommended two-step approach. Psychological Bulletin, 103(3), 41 1-423. Available at: https://doi.org/10.1037/0033-2909.103.3.41 1.

Argyris, C., \& Schon, D. (1978). Organizational learning: A theory of action perspective. Reading, MA: Addison-Wesley.

Armeli, S., Eisenberger, R. T., Fasolo, P., \& Lynch, P. (1998). Perceived organizational support and police performance: The moderating influence of socio-emotional needs. Journal of Applied Psychology, 83(2), 288-297. Available at: https://doi.org/10.1037/0021-9010.83.2.288.

Armstrong-Stassen, M., \& Schlosser, F. (2011). Perceived organizational membership and the retention of older workers. Journal of Organizational Behavior, 32(2), 319-344. Available at: https://doi.org/10.1002/job.647.

Bagozzi, R. P., \& Yi, Y. (1990). Assessing method variance in multitrait-multimethod matrices: The case of self-reported affect and perceptions at work. Journal of Applied Psychology, 75(5), 547-560. Available at: https://doi.org/10.1037/o0219010.75 .5 .547 .

Burris, E. R. (2012). The risks and rewards of speaking up: Managerial responses to employee voice. Academy of Management Journal, 55(4), 851-875. Available at: https://doi.org/10.5465/amj.2010.0562. 
Burris, E. R., Detert, J. R., \& Chiaburu, D. S. (2008). Quitting before leaving: The mediating effects of psychological attachment and detachment on voice. Journal of Applied Psychology, 93(4), 912. Available at: https://doi.org/10.1037/00219010.93.4.912.

Cabrera, A., Collins, W. C., \& Salgado, J. F. (2006). Determinants of individual engagement in knowledge sharing. International Journal Human Resource Management, 17, 245-264. Available at: https://doi.org/10.1080/09585190500404614.

Chen, Z., \& Aryee, S. (2007). Delegation and employee work outcomes: An examination of the cultural context of mediating processes in China. Academy of Management Journal, 50(1), 226-238. Available at: https://doi.org/10.5465/amj.2007.24162389.

Consultancy.uk. (2015). Deloitte: Employee engagement \#1 HR challenge. Retrieved from: http://www.consultancy.uk/news/1625/deloitteemployee-engagement-no-1-hr-challenge. [Accessed November, 16th , 2021$]$.

Crant, J. M. (2000). Proactive behavior in organizations. Journal of Management, 26(3), 435-462. Available at: https://doi.org/10.1177/014920630002600304.

Dalal, R. S. (2005). A meta-analysis of the relationship between organizational citizenship behavior and counterproductive work behavior. Journal of Applied Psychology, 90(6), 1241-1255. Available at: https://doi.org/10.1037/002 1-9010.90.6.1241.

Den Hartog, D. N., \& Belschak, F. D. (2007). Personal initiative, commitment and affect at work. Journal of Occupational and Organizational Psychology, 80(4), 601-622. Available at: https://doi.org/10.1348/096317906x 171442.

Detert, J. R., Burris, E. R., Harrison, D. A., \& Martin, S. R. (2013). Voice flows to and around leaders: Understanding when units are helped or hurt by employee voice. Administrative Science Quarterly, 58(4), 624-668. Available at: https://doi.org/10.1177/0001839213510151.

Detert, J. R., \& Burris, E. R. (2007). Leadership behavior and employee voice: Is the door really open? Academy of Management Journal, 5O(4), 869-884. Available at: https://doi.org/10.5465/amj.2007.26279183.

Detert, J. R., \& Treviño, L. K. (2010). Speaking up to higher-ups: How supervisors and skip-level leaders influence employee voice. Organization Science, 21(1), 249-270. Available at: https://doi.org/10.1287/orsc.1080.0405.

Dubois, D., Rucker, D. D., \& Galinsky, A. D. (2015). Social class, power, and selfishness: When and why upper and lower class individuals behave unethically. Journal of Personality and Social Psychology, 108(3), 436-449. Available at: https://doi.org/10.1037/pspioooooo8.

Dyne, L. V., Ang, S., \& Botero, I. C. (2003). Conceptualizing employee silence and employee voice as multidimensional constructs. Journal of Management Studies, 4O(6), 1359-1392. Available at: https://doi.org/10.1111/1467-6486.00384.

Edmondson, A. (1999). Psychological safety and learning behavior in work teams. Administrative Science Quarterly, 44(2), 350383. Available at: https://doi.org/10.2307/2666999.

Eisenberger, R., Armeli, S., Rexwinkel, B., Lynch, P., \& Rhoades, L. (2001). Reciprocation of perceived organizational support. The Journal of Applied Psychology, 86(1), 42-51. Available at: https://doi.org/10.1037/002 1-9010.86.1.42.

Flynn, F., Reagans, R., Amanatullah, E., \& Ames, D. (2006). Helping one's way to the top: Self-monitors achieve status by helping others and knowing who helps whom. Journal of Personality Social Psychology, 91(6), 1123-1137. Available at: https://doi.org/10.1037/0022-3514.91.6.1123.

Fornell, C. (1981). Structural equation models with unobservable variables and measurement error: Algebra and statistics. Journal of Marketing Research, 18(3), 382-388. Available at: https://doi.org/10.2307/3150980.

Frese, M., \& Fay, D. (2001). 4. Personal initiative: An active performance concept for work in the 21 st century. Research in Organizational Behavior, 23, 133-187. Available at: https://doi.org/10.1016/s0191-3085(01)23005-6.

Fuller, J. B., Marler, L. E., \& Hester, K. (2006). Promoting felt responsibility for constructive change and proactive behavior: Exploring aspects of an elaborated model of work design. Research in Organizational Behavior, 27, 1089-1120. Available at: https://doi.org/10.1002/job.408.

Hayes, A. F. (2018). Introduction to mediation, moderation and conditional process analysis, a regression based approach. New York: Guilford Press. 
Hofstede, G. (1991). Empirical models of cultural differences. In N. Bleichrodt \& P. J. D. Drenth (Eds.), Contemporary issues in cross-cultural psychology (pp. 4-20): Swets \& Zeitlinger Publishers.

Hongli, W., Feng, J., Prevellie, P., \& Wu, K. (2017). Why do I contribute when I am an "insider"? A moderated mediation approach to perceived insider status and employee’s innovative behavior. Journal of Organizational Change Management, 30(7), 1184-1197. Available at: https://doi.org/10.1108/jocm-06-2016-0109.

Hui, C., Lee, C., \& Wang, H. (2015). Organizational inducements and employee citizenship behavior: The mediating role of perceived insider status and the moderating role of collectivism. Human Resource Management, 54(3), 439-456. Available at: https://doi.org/10.1002/hrm.21620.

Kassing, J. W. (1997). Development of the intercultural willingness to communicate scale. Communication Research Reports, 14(4), 399-407. Available at: https://doi.org/10.1080/08824099709388683.

Kassing, J. W. (1998). Development and validation of the organizational dissent scale. Management Communication Quarterly, 12(2), 183-229. Available at: https://doi.org/10.1177/0893318998122002.

Kassing, J. W. (2011). Dissent in organizations. Cambridge, UK: Polity.

Lapalme, M. È., Stamper, C. L., Simard, G., \& Tremblay, M. (2009). Bringing the outside in: Can “external” workers experience insider status? Journal of Organizational Behavior: The International Journal of Industrial, Occupational and Organizational Psychology and Behavior, 30(7), 919-940.

LePine, J. A., \& Van Dyne, L. (1998). Predicting voice behavior in work groups. Journal of Applied Psychology, 83(6), 853-868. Available at: https://doi.org/10.1037/002 1-9010.83.6.853.

Liao, P.-Y. (2015). The role of self-concept in the mechanism linking proactive personality to employee work outcomes. Applied Psychology, 64(2), 421-443. Available at: https://doi.org/10.1111/apps.12003.

Liu, W., Song, Z. L., Li, X., \& Liao, Z. Y. (2017). Why and when leader's positive emotion promotes employee voice behavior. Academy of Management Journal, 60, 238-263. Available at: https://doi.org/10.5465/ambpp.2013.13627abstract.

McMillan, D. W., \& Chavis, D. M. (1986). Sense of community: A definition and theory. Journal of Community Psychology, 14(1), 6-23. Available at: https://doi.org/10.1002/1520-6629(198601)14:1\%3C6::aid-jcop2290140103\%3E3.0.co;2-i.

Mikulincer, M., Shaver, P., Sapir-Lavid, Y., \& Avihou-Kanza, N. (2009). What's inside the minds of securely and insecurely attached people? The secure-base script and its associations with attachment-style dimensions. Journal of Personality and Social Psychology, 97(4), 615-633. Available at: https://doi.org/10.1037/a0015649.

Morrison, E., \& Milliken, F. (2003). Shades of silence: Emerging themes and future directions for research on silence in organizations. Journal of Management Studies, 4O(6), 1563-1568. Available at: https://doi.org/10.1111/14676486.00391.

Ng, T. W. H., \& Feldman, D. C. (2012). The effects of organizational and community embeddedness on work-to-family and family-to-work conflict. Journal of Applied Psychology, 97(6), 1233-1251. Available at: https://doi.org/10.1037/a0029089.

Ng, T. W., \& Feldman, D. C. (2015). Ethical leadership: Meta-analytic evidence of criterion-related and incremental validity. Journal of Applied Psychology, 100(3), 948-965. Available at: https://doi.org/10.1037/a0038246.

Organ, D. W. (1988). Organizational citizenship behavior: The good soldier syndrome. Lexington: Books/D. C. Heath and Com.

Podsakoff, P. M., MacKenzie, S. B., \& Podsakoff, N. P. (2012). Sources of method bias in social science research and recommendations on how to control it. Annual Review of Psychology, 63(1), 539-569. Available at: https://doi.org/10.1146/annurev-psych-120710-100452.

Rajan, D. (2018). Negative impacts of heavy workload: A comparative study among sanitary workers. Sociology International Journal, 2(6), 465-474. Available at: https://doi.org/10.15406/sij.2018.02.00086.

Relph, E. (1976). Place and placelessness. London: Pion.

Spector, P. E., \& Brannick, M. T. (2011). Methodological urban legends: The misuse of statistical control variables. Organizational Research Methods, 14(2), 287-305. Available at: https://doi.org/10.1177/1094428110369842. 
Srivastava, A., Bartol, K. M., \& Locke, E. A. (2006). Empowering leadership in management teams: Effects on knowledge sharing, efficacy, and performance. Academy of Management Journal, 49(6), 1239-1251. Available at: https://doi.org/10.5465/amj.2006.23478718.

Stamper, C. L., \& Masterson, S. S. (2002). Insider or outsider? How employee perceptions of insider status affect their work behavior. Journal of Organizational Behavior: The International Journal of Industrial, Occupational and Organizational Psychology and Behavior, 23(8), 875-894. Available at: https://doi.org/10.1002/job.175.

Sui, Y., \& Wang, H. (2014). Relational evaluation, organization-based self-esteem, and performance: The moderating role of allocentrism. Journal of Leadership \& Organizational Studies, 21(1), 17-28. Available at: https://doi.org/10.1177/1548051813486833.

Sui, Y., \& Wang, H. (2013). Relational evaluation, organization-based self-esteem, and performance: The moderating role of allocentrism. Journal of Leadership Organizational Studies, 21, 17-28. Available at: https://doi.org/10.1177/1548051813486833.

Tajfel, H. (1982). Social identity and interegroup relations. Cambridge, UK: Cambridge University Press.

Tajfel, H., \& Turner, J. C. (1979). An integrative theory of intergroup conflict. In Austin, W. G., \& Worchel, S. (Eds.), The social psychology of intergroup relations (pp. 33-47). Monterey, CA, US: Brooks/Cole.

Tajfel, H., \& Turner, J. C. (1986). The social identity theory of intergroup behavior. In S. Worchel \& W. G. Austin (Eds.), Psychology of intergroup relations (pp. 7-24). Chicago, IL: Nelson Hall.

Turner, J. C., \& Onorato, R. S. (1999). Social identity, personality, and the self-concept: a self-categorization perspective. In Tyler, T.R., Kramer, R.M. and John, O.P. (Eds.), The Psychology of the Social Self (pp. 11-46). Mahwah, NJ: Lawrence Erlbaum Associates.

Van Dyne, L., \& LePine, J. A. (1998). Helping and voice extra-role behaviors: Evidence of construct and predictive validity. Academy of Management Journal, 41(1), 108-119. Available at: https://doi.org/10.5465/256902.

Wang, J., \& Kim, T.-Y. (2013). Proactive socialization behavior in China: The mediating role of perceived insider status and the moderating role of supervisors' traditionality. Journal of Organizational Behavior, 34(3), 389-406. Available at: https://doi.org/10.1002/job.1811.

Zhou, J., \& George, J. M. (2001). When job dissatisfaction leads to creativity: Encouraging the expression of voice. Academy of Management Journal, 44(4), 682-696. Available at: https://doi.org/10.2307/3069410.

Views and opinions expressed in this article are the views and opinions of the author(s), International Journal of Management and Sustainability shall not be responsible or answerable for any loss, damage or liability, etc. caused in relation to/arising out of the use of the content. 